\title{
Systemic administration of curcumin nanoparticles protects ischemia-reperfusion injury in ovaries: An animal model study
}

 \\ ${ }^{1}$ Maternal and Childhood Obesity Research Center, Department of Infertility, Urmia University of Medical Sciences, Urmia, Iran \\ 2Department of Anatomical Sciences, Faculty of Medicine and Razi Herbal Medicines Research Center, Lorestan University of Medical Sciences, Khorramabad, Iran \\ ${ }^{3}$ Department of Pathology, Faculty of Medicine, Urmia University of Medical Sciences, Urmia, Iran \\ ${ }^{4}$ Student Research Committee, Urmia University of Medical Sciences, Urmia, Iran
}

Study conducted at Urmia University of Medical Sciences, Urmia, Iran

Article received: $4 / 25 / 2017$ Accepted for publication: 5/20/2017

*Correspondence:

Maternal and Childhood Obesity Research Center, Department of Infertility, Urmia University of Medical Sciences Address: Nazloo Road Urmia - Iran

Postal code: 5714783734 mohaddesi.h@umsu.ac.ir

http://dx.doi.org/10.1590/1806-9282.64.01.22

\section{SUMMARY}

Objective: Ovarian torsion must be diagnosed and treated as early as possible. The aim of the present study was to investigate the effects of intraperitoneal administration of nanocurcumin on ischemia-reperfusion injury in ovaries. Method: Thirty-five (35) healthy female Wistar rats weighing approximately $250 \mathrm{~g}$ were randomized into seven experimental groups ( $\mathrm{n}=5)$ : Group SSG - The rats underwent only laparotomy. Group I: A 3-hour ischemia only. Group I/R: A 3-hour ischemia and 3-hour reperfusion. Group I/C: A 3-hour ischemia only, and $1 \mathrm{mg} / \mathrm{kg}$ intraperitoneal administration of curcumin 2.5 hours after induction of ischemia. Group I/R/C: A 3-hour ischemia, 3-hour reperfusion, and $1 \mathrm{mg} / \mathrm{kg}$ intraperitoneal administration of curcumin 2.5 hours after induction of ischemia. Group I/NC: A 3-hour ischemia only and $1 \mathrm{mg} / \mathrm{kg}$ intraperitoneal administration of nanocurcumin 2.5 hours after induction of ischemia. Group I/R/C: A 3-hour ischemia, 3-hour reperfusion and $1 \mathrm{mg} / \mathrm{kg}$ intraperitoneal administration of nanocurcumin 2.5 hours after induction of ischemia.

Results: Nanocurcumin-treated animals showed significantly improved development of ischemia and reperfusion tissue injury compared to those in the other groups ( $p<0.05)$. Significant higher values of SOD, tGSH, GPO, GSHRd and GST were observed in $\mathrm{I} / \mathrm{R} / \mathrm{NC}$ animals compared to those in the other groups ( $\mathrm{p}<0.05$ ). The damage indicators (NOS, MDA, MPO and DNA damage level) were significantly lower in $\mathrm{I} / \mathrm{R} / \mathrm{NC}$ animal compared to those of other groups ( $\mathrm{p}<0.05)$.

Conclusion: Intraperitoneal administration of nanocurcumin can be helpful in minimizing ischemia-reperfusion injury in ovarian tissue exposed to ischemia.

Keywords: Curcumin. Nanoparticles. Ovary.

\section{INTRODUCTION}

There are various conditions, such as long mesovarium and adnexal venous congestion, that could result in torsion of ovary and subsequently obstruction of the ovarian vessels. This causes a life-threatening reduction in tissue blood flow and permanent tissue damage. ${ }^{1}$ Therefore, ovarian torsion must be diagnosed and treated as early as possible to preserve ovarian function and prevent future infertility. ${ }^{2}$ Upon detection of ovarian torsion, detorsion of the twisted adnexa and evaluation of tissue reperfusion is proposed to prevent future infertility even in case of cyanotic tissues. ${ }^{2,3}$ This ovarian torsion-detorsion process is named ischemia-reperfusion injury. ${ }^{4}$

Reperfusion of the ischemic tissue leads to much more serious damage to the tissue than the damage caused by ischemia. ${ }^{5}$ Reperfusion-related damage in the cell is created by many factors, mostly including oxygen-derived free radicals, which are rapidly generated in the tissue as a result of reperfusion. ${ }^{6}$ Due to physiological or pathological alterations, oxidative damage takes place with changes favoring the oxidation process. ${ }^{7}$ Prompt diagnosis to reduce ischemic and reperfusion injury and its consequences is 
still unachievable with this approach. Therefore, studies on prevention of reperfusion injury seem very important. ${ }^{8}$

A proposed pathogenesis for tissue injury during reperfusion is the accumulation of activated neutrophils that release reactive oxygen species. ${ }^{9}$ Lipid peroxidation in the cell is the most deleterious effects of free radicals that ultimately reduce the membrane potential and subsequently cause cell injury. Malondialdehyde (MDA), one of the end products of lipid peroxidation, also results in severe cell damage by inducing polymerization and cross linking in membrane components. ${ }^{10}$ Free oxygen radicals react with DNA and form 8-hydroxyguanine (8-OHGua), which is one of the products of DNA damage. ${ }^{11}$ In spite of the fact that generation of free oxygen radicals occurs continuously in cells, the presence of endogenous antioxidant defense systems preserves tissues from the harmful effects of free oxygen radicals. ${ }^{12}$ Various agents, antiinflammatory and antioxidant free radical scavengers have been reported with promising beneficial effects on prevention of ischemic/reperfusion injuries in tissues. ${ }^{13-16}$

Curcumin is the main phenolic pigments extracted from turmeric, the powdered rhizome of Curcuma longa, along with demethoxycurcumin and bisdemethoxycurcumin. ${ }^{17}$ Extensive research indicates that curcumin possesses potent antioxidant and anti-inflammatory properties, and inhibits lipid peroxidation and scavenges superoxide anion, singlet oxygen, nitric oxide and hydroxyl radicals. ${ }^{18-20}$ Administration of curcumin has been reported to be effective in reversing tissue damage induced by ischemia reperfusion injury in ovarian torsion. ${ }^{21}$

Curcumin, a naturally-occurring polyphenolic compound, is considerably promising; however, its poor water solubility and fast degradation profile compromise its bioavailability way below the threshold level on administration. Over a period of time, strong emphasis has been given to improve the biodistribution of native curcumin, but only recently the application of the field of nanotherapeutics has significantly improved its therapeutic efficacy. This is through the development of nanorange formulations of curcumin, popularly known as the nanocurcumin. ${ }^{22}$

The physiologic characteristic of the peritoneal cavity, which helps remove toxic metabolites from the body, has been successfully exploited to provide peritoneal dialysis in end stage renal disease patients. ${ }^{23}$ The same characteristics of the peritoneal membrane also provide a useful doorway in the body for several pharmacological agents. One advantage would be that the drug achieves therapeutic efficacy in the target site while minimizing the systemic toxicities. Intraperitoneal administration seems more effective and may increase drug availability if oral administration poses any difficulties. It is clear that transperitoneal absorption of the drug is much faster than oral administration. ${ }^{24}$

The present study was different from other studies in the literature for using nanocurcumin on ischemia/ reperfusion injury. Aimed to study peritoneal effects of nanocurcumin on ischemia/reperfusion injury, our study was designed to determine if nanocurcumin could in fact protect against ischemia/reperfusion-induced ovarian damage. The assessments were based on histopathological and biochemical parameters.

\section{Method}

\section{Study design and animals}

Two weeks before and during the experiments, the animals were housed in individual plastic cages at room temperature $\left(23 \pm 3^{\circ} \mathrm{C}\right)$, stable air humidity and a natural day/night cycle. The rats had free access to standard rodent laboratory food and tap water. All measurements were made by two blinded observers unaware of the analyzed groups. The present study was designed and modified based on a method described by Oral et al., 2010. Thirty-five (35) healthy female Wistar rats weighing approximately $250 \mathrm{~g}$ were randomized into seven experimental groups ( $\mathrm{n}=5$ ): SSG (SSG Surgery Group) - The rats underwent only laparotomy; group I - A 3-hour ischemia only; group I/R - A 3-hour ischemia and a 3-hour reperfusion; group I/C - A 3-hour ischemia only and $100 \mathrm{mg} / \mathrm{kg}$ intraperitoneal administration of curcumin (Sigma-Aldrich Chemie Gmbh, Steinheim, Germany) 2.5 hours after induction of ischemia; group I/R/C - A 3-hour ischemia, a 3-hour reperfusion and $100 \mathrm{mg} /$ $\mathrm{kg}$ intraperitoneal administration of curcumin 2.5 hours after induction of ischemia; group I/NC - A 3-hour ischemia only and $1 \mathrm{mg} / \mathrm{kg}$ intraperitoneal administration of nanocurcumin (Sigma-Aldrich Chemie Gmbh, Steinheim, Germany) 2.5 hours after induction of ischemia; group I/R/NC - A 3-hour ischemia, a 3-hour reperfusion and $1 \mathrm{mg} / \mathrm{kg}$ intraperitoneal administration of nanocurcumin 2.5 hours after induction of ischemia. The right ovaries were transferred to a $10 \%$ formaldehyde solution for histopathological assessments and the left ovaries were dissected free of surrounding soft tissues and then stored in a freezer at $-80^{\circ} \mathrm{C}$ for biochemical assessments.

\section{Preparation of nanocurcumin}

Nanocurcumin was prepared using a method previously described by other authors. In brief, curcumin $(100 \mathrm{mg}$, $0.27 \mathrm{mmol}$ ) was placed in dichloromethane $(20 \mathrm{~mL})$, and 
$1 \mathrm{~mL}$ of this solution was sprayed into boiling water $(50 \mathrm{~mL})$ dropwise with a flow rate of $0.2 \mathrm{~mL} / \mathrm{min}$ for 5 minutes under ultrasonic conditions, with an ultrasonic power of $100 \mathrm{~W}$ and a frequency of $30 \mathrm{kHz}$. After sonication for 10 minutes, the contents were stirred at 200-800 rpm at room temperature for about 20 minutes when a clear orange-colored solution was obtained. The solution was concentrated under reduced pressure at $50^{\circ} \mathrm{C}$ and then freeze-dried to obtain an orange powder. A co-TLC of the powdered sample with standard curcumin showed both to have the same Rf values. $1 \mathrm{H}$ NMR and ultraviolet (UV) spectra of the lyophilized powder confirmed it to be curcumin. Maintaining the drop flow was significant for both forming nanoparticles and maintaining size uniformity. The mean particle diameter of curcumin nanoparticles was measured by dynamic light scattering (DLS) performed on Malvern Zetasizer S90 series. The sample was prepared by taking $1 \mathrm{mg}$ of the lyophilized nanocurcumin powder in $10 \mathrm{~mL}$ of distilled water. Transmission electron micrograph (TEM) analysis was performed on a Morgagni $268 \mathrm{D}$ from FEI. The sample was prepared by placing a drop of the aqueous dispersion of curcumin nanoparticles on the copper grid and allowing it to air dry. Scanning electron micrograph (SEM) of the aqueous dispersion was recorded on a Jeol JSM 840 microscope by spreading the nanoparticles dispersion over a carbon tape and drying it under nitrogen stream. The sample was then coated in a sputter coater (EMITECH K $550 \mathrm{x}$ ) with a gold layer under vacuum conditions. ${ }^{25}$

\section{Surgical procedure}

Animals were anesthetized by intraperitoneal administration of ketamine-xylazine (ketamine $5 \%, 90 \mathrm{mg} / \mathrm{kg}$ and xylazine $2 \%, 5 \mathrm{mg} / \mathrm{kg}$ ). The procedure was carried out based on the guidelines of the Ethics Committee of the International Association for the Study of Pain. ${ }^{26}$ The Ethical Committee of the Urmia University of Medical Sciences approved all the experiments.

A longitudinal midline incision was made in the lower abdomen and the uterine horns and adnexa were exposed. In order to induce ischemia, a vascular clamp was applied on the rats' ovary vessels. After a 3-hour period of ischemia, both ovaries were surgically dissected for histopathological and biochemical assessments. To induce ischemia/reperfusion, both ovaries underwent ischemia the same way and, at the end of a 3-hour period, the vascular clamps were chosen, removed and a 3-hour reperfusion was obtained. Then, the ovaries were dissected for histopathological and biochemical assessments.

\section{Histopathological assessments}

The ovaries were fixed in $10 \%$ buffered formalin for 24 hours. The tissue samples were then processed and embedded in paraffin (5- $\mu \mathrm{m}$ semithin sections). The samples were then dewaxed, rehydrated and stained routinely with hematoxylin and eosin. The sections were then observed under a light photomicroscope. For semithin sections, ovaries were fixed in $2.5 \%$ buffered glutaraldehyde and postfixed in $2 \% \mathrm{OsO}_{4}$ for $2 \mathrm{~h}$, dehydrated in a graded ethanol series and embedded in epon resin. Semithin transverse sections $(5 \mu \mathrm{m})$ were next stained with toluidine blue and examined under a light microscope.

\section{Biochemical assessments}

Tissue processing for biochemical assessments of ovaries

The ovary tissue samples were kept at $-80^{\circ} \mathrm{C}$ for 3 days, and then enzyme activities were determined in rat ovary tissues. The ovary tissues were ground under liquid nitrogen using a mortar. One half gram was weighed for each group and then treated with $4.5 \mathrm{~mL}$ of an appropriate buffer. This mixture was homogenized on ice with use of an ultra-turrax homogenizer (IKA, Werke, Germany) for 15 minutes. Homogenates were filtered and centrifuged by using a refrigerator centrifuge at $4^{\circ} \mathrm{C}$. Then the supernatants were used to determine the enzymatic activities. All assays were carried out at room temperature.

\section{Superoxide dismutase (SOD) analysis}

Superoxide dismutase estimation was based on the generation of superoxide radicals produced by xanthine and the xanthine oxidase system, which reacts with nitroblue tetrazolium to form formazan dye. ${ }^{27}$ Superoxide dismutase activity was then measured at $560 \mathrm{~nm}$ by the degree of inhibition of this reaction and is expressed as millimoles per minute per milligram of tissue.

\section{Nitric oxide synthase (tNOS) activity}

Nitric oxide synthase activity of rat ovaries was measured spectrophotometrically using the oxidation of oxyhemoglobin to methemoglobin by $\mathrm{NO}$ as described by other authors. ${ }^{28}$ The absorption difference between 401 and $421 \mathrm{~nm}$ was continuously monitored with a dual wave length recording spectrophotometer at $37^{\circ} \mathrm{C}$. For the total NOS (tNOS) assay, the incubation medium contained $1.6 \mathrm{mmol} / \mathrm{L}$ oxyhemoglobin, $200 \mathrm{mmol} / \mathrm{L} \mathrm{CaCl}_{2}, 1 \mathrm{mmol} / \mathrm{L}$ $\mathrm{MgCl}_{2}, 100 \mathrm{mmol} / \mathrm{L}$ L-arginine, $100 \mathrm{mmol} / \mathrm{L}$ of the reduced form of nicotinamide-adenine dinucleotide phosphate, $40 \mathrm{mmol} / \mathrm{L}$ potassium phosphate ( $\mathrm{pH} 7.2), 1$ $\mathrm{mmol} / \mathrm{L}$ NG-nitro-L-arginine and $10 \%$ (vol/vol) tissue extract with $50 \mathrm{mmol} / \mathrm{L} \mathrm{L}$-valine to inhibit arginase. ${ }^{29}$ 


\section{Malondialdehyde (MDA) analysis}

Concentrations of ovarian lipid peroxidation were determined by estimating MDA using the thiobarbituric acid test. ${ }^{30}$ The rat ovaries were rinsed with cold saline. The corpus mucosa was scraped, weighed and homogenized in $10 \mathrm{~mL}$ of $100 \mathrm{~g} / \mathrm{L} \mathrm{KCl}$. The homogenate $(0.5 \mathrm{~mL})$ was added to a solution containing 2-thiobarbiturate $(1.5 \mathrm{~mL}$ of $8 \mathrm{~g} / \mathrm{L})$, acetic acid $(1.5 \mathrm{~mL}$ of $200 \mathrm{~g} / \mathrm{L})$, sodium lauryl sulfate $(0.2 \mathrm{~mL}$ of $80 \mathrm{~g} / \mathrm{L})$ and distilled water $(0.3 \mathrm{~mL})$. The mixture was incubated at $98^{\circ} \mathrm{C}$ for 1 hour. n-butanol: pyridine $5 \mathrm{~mL}$ (ratio:15:1) was then added. The mixture was vortexed for $1 \mathrm{~min}$ and centrifuged for $30 \mathrm{~min}$ at 4,000 rpm. Absorbance of the supernatant was measured at $532 \mathrm{~nm}$ using a spectrophotometer. The standard curve was obtained by using 1,1,3,3-tetramethoxypropane.

\section{Myeloperoxidase (MPO) analysis}

The activity of MPO in the total homogenate was measured according to previously described methods. ${ }^{31}$ The sample was weighed and homogenized in $2 \mathrm{~mL}$ of $50 \mathrm{mmol} / \mathrm{L}$ phosphate buffer containing $0.5 \%$ hexadecyl trimethyl ammonium bromide (HDTMAB) and centrifuged at 3,500 rpm for $60 \mathrm{~min}$ at $4^{\circ} \mathrm{C}$. The supernatant was used to determine MPO activity using $1.3 \mathrm{~mL}$ 4-aminoantipyrine- $2 \%$ phenol (25 mM) solution. $25 \mathrm{mmol} / \mathrm{L} 4$-aminoantipyrine-2\% phenol solution and $0.0005 \% 1.5 \mathrm{~mL} \mathrm{H}_{2} \mathrm{O}_{2}$ were added and equilibrated for 3-4 minutes. After establishing the basal rate, a sample suspension $(0.2 \mathrm{~mL})$ was added and mixed. Increases in absorbance at $510 \mathrm{~nm}$ for $4 \mathrm{~min}$ at 0.1 - $\mathrm{min}$ intervals were recorded. Absorbance was measured at $412 \mathrm{~nm}$.

\section{Total glutathione (tGSH) analysis}

The amount of GSH in the total homogenate was measured according to the previously described methods, with some modifications. ${ }^{32}$ The sample was homogenized at $\mathrm{pH} 7.5$, in Tris-HCl buffer $(2 \mathrm{~mL}$ of $50 \mathrm{mmol} / \mathrm{L})$. The homogenate was precipitated with trichloroacetic acid $(0.1 \mathrm{~mL}$ of $25 \%)$, and the precipitate was removed after centrifugation at $4,200 \mathrm{rpm}$ at $4^{\circ} \mathrm{C}$ for 40 minutes; the supernatant was used to measure GSH level. A total of $1,500 \mu \mathrm{L}$ of measurement buffer $(200 \mathrm{mmol} / \mathrm{L}$ Tris- $\mathrm{HCl}$ buffer containing $0.2 \mathrm{mmol} / \mathrm{L}$ EDTA at $\mathrm{pH} 7.5), 500 \mu \mathrm{L}$ supernatant, $100 \mu \mathrm{L}$ DTNB $(10 \mathrm{mmol} / \mathrm{L})$ and $7,900 \mu \mathrm{L}$ methanol were added to a tube and vortexed and incubated for 30 minutes at $37^{\circ}$ C. 5,5-dithiobis (2- nitrobenzoic acid) (DTNB) was used as a chromogen; it formed a yellow-colored complex with sulfhydryl groups. Absorbance was measured at $412 \mathrm{~nm}$ using a spectrophotometer (Beckman DU 500, USA). The standard curve was obtained using reduced glutathione.

\section{Glutathione peroxidase (GPO) analysis}

GPO activity was determined according to the method of Lawrence and Burk. ${ }^{33}$ After tissue homogenization, supernatant was used for GPO measurement. Following the addition of $\mathrm{KH}_{2} \mathrm{PO}_{4}$, EDTA, GSH, B-NADPH, $\mathrm{NaN}_{3}$ and $\mathrm{GR}$, the mixture was incubated. As soon $\mathrm{H}_{2} \mathrm{O}_{2}$ was added, the chronometer was turned on and the absorbance at $340 \mathrm{~nm}$ was recorded for 5 minutes every 15 seconds.

\section{Glutathione reductase (GSHRd) analysis}

GR activity was determined spectrophotometrically by measuring the rate of NADPH oxidation at $340 \mathrm{~nm}$ according to Carlberg and Mannervik method. ${ }^{34}$ After tissue homogenization, supernatant was used for GR measurement. After NADPH and GSSG were added, a chronometer was set on and absorbance was measured for 5 minutes with 30 minutes intervals at $340 \mathrm{~nm}$ spectrophotometrically.

\section{Glutathione S-transferase (GST) activity}

GST activity was determined by Habig and Jakoby. ${ }^{35}$ Enzyme activity was determined in a $4-\mathrm{mL}$ cuvette containing $30 \mathrm{mM}$ GSH, $30 \mathrm{mM}$ 1-chloro-2,6-dinitrobenzene, 0.1 M PBS ( $\mathrm{pH} 6.5$ ), and tissue homogenate at $340 \mathrm{~nm}$ using a spectrophotometer.

\section{Isolation of DNA from ovarian tissue}

DNA isolation was performed using a method previously described by other authors. ${ }^{8}$ In brief, the tissue samples were homogenized at $4^{\circ} \mathrm{C}$ in $1 \mathrm{~mL}$ of homogenization buffer $(0.1$ $\mathrm{M} \mathrm{NaCl}, 30 \mathrm{mM}$ Tris, $\mathrm{pH}$ 8.0, 10 mM EDTA, $10 \mathrm{mM}$ 2-mercaptoethanol, $0.5 \%(\mathrm{v} / \mathrm{v})$ Triton X-100) with six passes of a Teflon-glass homogenizer at $200 \mathrm{rpm}$. The samples were centrifuged at $4^{\circ} \mathrm{C}$ for $10 \mathrm{~min}$ at $1,000 \mathrm{~g}$ to pellet nuclei. The supernatant was discarded, and the crude nuclear pellet re-suspended and re-homogenized in $1 \mathrm{~mL}$ of extraction buffer (0.1 M Tris, pH 8.0, 0.1 M NaCl, 20 mM EDTA) and re-centrifuged as above for $2 \mathrm{~min}$. The washed pellet was re-suspended in $300 \mu \mathrm{L}$ of extraction buffer with a wide orifice $200 \mu \mathrm{L}$ Pipetman tip. The re-suspended pellet was subsequently incubated at $65^{\circ} \mathrm{C}$ for 1 hour with the presence of $0.1 \mathrm{~mL}$ of $10 \% \mathrm{SDS}, 40 \mu \mathrm{L}$ proteinase $\mathrm{K}$, and $1.9-\mathrm{mL}$ leukocyte lysis buffer. Then, ammonium acetate was added to the crude DNA sample to yield a final concentration of $2.5 \mathrm{~mol} / \mathrm{L}$, and centrifuged in a micro centrifuge for 5 minutes. The supernatant was removed and mixed with two volumes of ethanol to precipitate the DNA fraction. After centrifugation, the pellet was dried under reduced pressure and dissolved in sterile water. The absorbance of this fraction was measured at 260 and $280 \mathrm{~nm}$. Purification of DNA was determined as A 260/280 ratio 1.8. 


\section{cDNA hydrolysis with formic acid}

DNA hydrolysis with formic acid was performed based on a modified method described by other authors. ${ }^{8}$ Briefly, $50 \mathrm{mg}$ of DNA were hydrolyzed with $0.5 \mathrm{~mL}$ of formic acid $(60 \%, v / v)$ for 45 minutes at $150^{\circ} \mathrm{C}$. The tubes were allowed to cool. The contents were then transferred to Pierce micro-vials, covered with Kleenex tissues cut to size, secured in place using a rubber band and cooled in liquid nitrogen. Formic acid was removed by freeze-drying and prior to analysis by HPLC they were re-dissolved in the eluent, final volume $200 \mu \mathrm{L}$.

\section{Measurement of 8-hydroxy-2 deoxyguanine (8-OH Gua)}

Measurement of 8-hydroxy-2 deoxyguanine (8-OH Gua) was performed based on a modified method described by others. ${ }^{8}$ Briefly, the amount of 8-OH gua and guanine (Gua) was measured using a HPLC system equipped with an electrochemical detector, HP Agilent 1,100 module series and E.C.D. HP 1049 A. The amount of 8-OH gua and Gua was analyzed on a $2504.6 \mathrm{~mm}$ Supelco LC-18-S reverse-phase column. The mobile phase was $50 \mathrm{mM}$ potassium phosphate, $\mathrm{pH} 5.5$, with acetonitrile, a $97 \mathrm{vol}-$ ume acetonitrile and a 3 volume potassium phosphate, and the flow rate was $1.0 \mathrm{~mL} / \mathrm{min}$. The detector potential was set at $0.80 \mathrm{~V}$ for measuring the oxidized base. Gua and $8-\mathrm{OH}$ Gua $(25 \mathrm{pmol})$ were used as standards. The $8-\mathrm{OH}$ gua levels were expressed as the number of $8-\mathrm{OH}$ gua molecules/105 Gua molecules.

\section{Statistical analysis}

Experimental results were expressed as mean \pm SD. Statistical analyses were performed using PASW 18.0 (SPSS Inc., Chicago, IL, USA). Model assumptions were evaluated by examining the residual plot. Results were analyzed using repeated measures and a factorial ANOVA with two betweensubject factors. Bonferroni test for pairwise comparisons was used to examine the effect of time and treatments. The differences were considered significant when $\mathrm{p}<0.05$.

\section{Results}

\section{Histopathological findings}

The histologic design of the ovarian tissue in the SSG animals was normal. Ovarian tissues in the ischemia group showed condensed hemorrhage and severe vascular congestion along with degenerative and necrotic changes in many of the cells. The tissues in the I/R group showed histopathological changes of condensed hemorrhage, infiltration of inflammatory cells along with degenerative and apoptotic cells. Polymorphonuclear leukocytes (neutrophils) were dominant cell types. In I/R/C group gen- eral histologic and cellular structures of the tissues were not normal in appearance; however, mild vascular congestion and edema were observed. In I/R/NC group only a slightly mild hemorrhage was around ovarian follicles. The general histologic structure of the ovarian tissue in this group was normal and no important pathologic findings in the structural level were observed except for only a slightly mild inflammation, vascular congestion and edema (Figure 1).

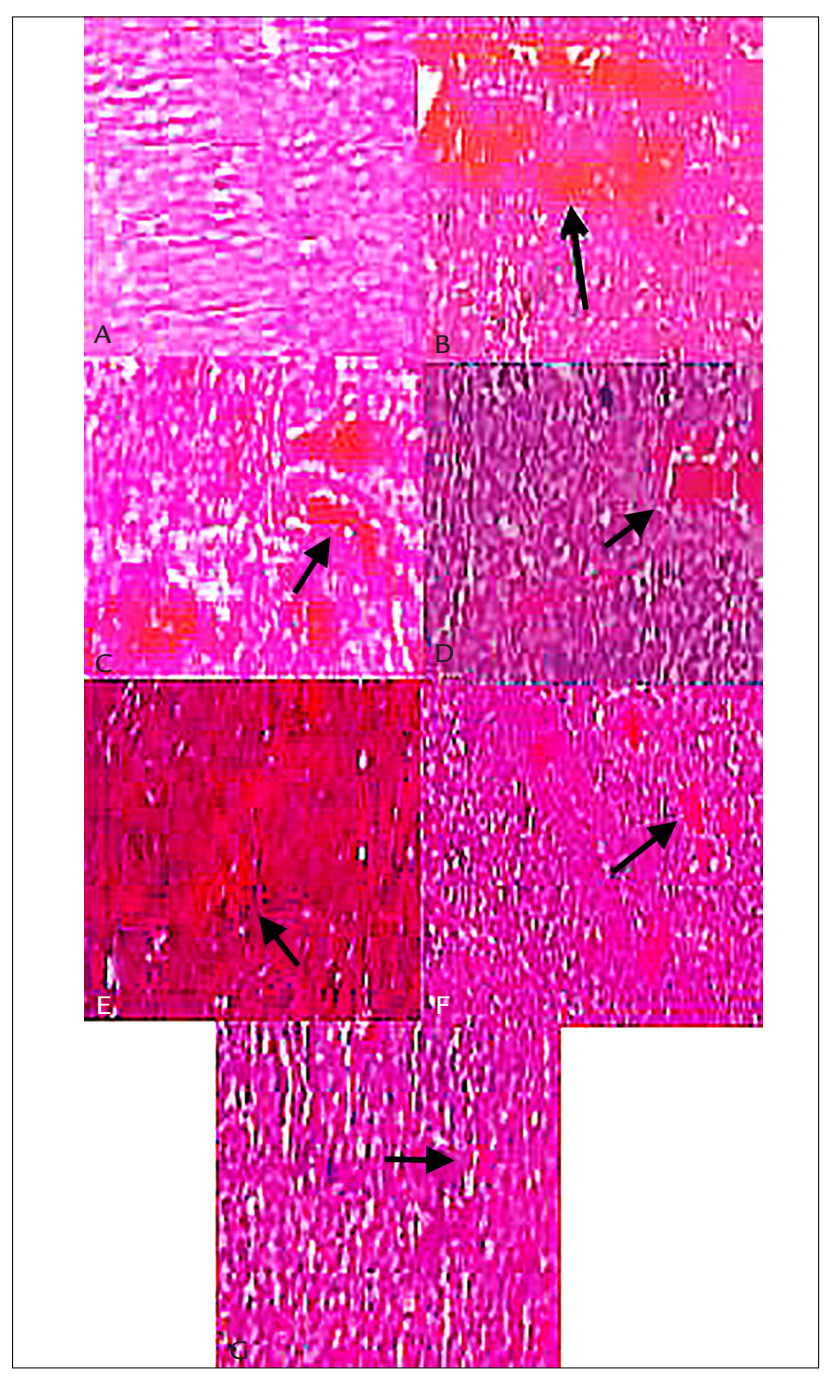

FIGURE 1 Histologic micrographs of ovarian tissue in SSG (A), I (B), I/R (C), I/C (D), I/R/C (E), I/NC (F) and I/R/NC (G) groups. Micrograph $\mathrm{B}$ shows condensed hemorrhage and severe vascular congestion (arrow), as well as severe edema (arrowhead). Micrograph $C$ shows condensed hemorrhage and vascular congestion (arrow), as well as edema (arrowhead). Micrograph D shows moderate vascular congestion (arrow) and moderate edema (arrowhead). Micrograph E shows mild vascular congestion and edema (arrow). Micrographs F and G show slightly mild vascular congestion and edema (arrows). Scale bar: $200 \mu \mathrm{m}$. 
The numerical densities of neutrophils were also estimated at $15 \times 10^{-6} / \mu^{3}, 11 \times 10^{-6} / \mu^{3}, 17 \times 10^{-6} / \mu^{3}$, $16 \times 10^{-6} / \mu \mathrm{m}^{3}$ and $12 \times 10^{-6} / \mu^{3}, 15 \times 10^{-6} / \mu \mathrm{m}^{3}, 10 \times$ $10^{-6} / \mu^{3}{ }^{3}$ in SSG, I, I/R, I/C, I/R/C, I/NC and I/R/NC groups, respectively.

\section{Biochmical findings}

Superoxide dismutase (SOD) analysis

The value of SOD activity was $69.5 \pm 0.57 \mathrm{mmol} / \mathrm{min} / \mathrm{mg}$ tissue in the SSG group. The values of SOD declined to $35.8 \pm 0.22$ and $57.2 \pm 0.21 \mathrm{mmol} / \mathrm{min} / \mathrm{mg}$ tissue in I and I/R groups, respectively. However, intraperitoneal administration of $1 \mathrm{mg} / \mathrm{kg}$ of nanocurcumin reversed the trend and increased the activity of SOD to $78.2 \pm 0.31 \mathrm{mmol} /$ $\mathrm{min} / \mathrm{mg}$ tissue in the ovarian tissue in $\mathrm{I} / \mathrm{R} / \mathrm{NC}$ group. The value of SOD activity in $\mathrm{I} / \mathrm{R} / \mathrm{NC}$ group was significantly higher than those of the other experimental groups $(\mathrm{p}<0.05)$ (Table 1).

\section{Nitric oxide synthase (NOS) activity}

The value of tNOS activities was increased in I and I/R groups and was significantly higher than those of SSG group $(\mathrm{p}<0.05)$. However, intraperitoneal administration of $1 \mathrm{mg} / \mathrm{kg}$ of nanocurcumin reversed the trend and decreased tNOS activity in the rats' ovary. In I/R/NC group the value of tNOS activity was significantly lower than those of the other experimental groups $(\mathrm{p}<0.05)$ (Table 1$)$.

\section{Malondialdehyde (MDA) analysis}

The results of the present study showed that concentration of MDA in SSG group was $5.7 \pm 0.19 \mu \mathrm{mol} / \mathrm{g}$ protein in ovarian tissue. MDA level in I/R group was signifi- cantly increased to $11.6 \pm 0.23 \mu \mathrm{mol} / \mathrm{g}$ protein $(\mathrm{p}<0.01)$. Intraperitoneal administration of nanocurcumin significantly decreased the levels of MDA in ovarian tissues of $\mathrm{I} / \mathrm{R} / \mathrm{NC}$ animals $(\mathrm{p}<0.05)$ (Table 1$)$.

\section{Myeloperoxidase (MPO) analysis}

The level of MPO was significantly increased in I and I/R groups ( $p<0.05)$. Intraperitoneal administration of nanocurcumin reversed the trend and significantly decreased the levels of MPO in ovarian tissues of $\mathrm{I} / \mathrm{R} / \mathrm{NC}$ animals $(\mathrm{p}<0.05)$ (Table 1).

\section{Total glutathione (tGSH) analysis}

The values for $t G S H$ levels were $9.8 \pm 0.33$ and $4.9 \pm 0.31$ $\mathrm{nmol} / \mathrm{g}$ protein in SSG and I/R animals, respectively. Intraperitoneal administration of nanocurcumin significantly increased the levels of GSH in ovarian tissues of $\mathrm{I} / \mathrm{R} / \mathrm{NC}$ animals $(\mathrm{p}<0.05)$ (Table 1$)$.

\section{Glutathione peroxidase (GPO) analysis}

The values for GPO levels were $38.6 \pm 2.64$ and $17.6 \pm 1.41$ $\mathrm{u} / \mathrm{g}$ protein in SSG and I/R animals, respectively. Intraperitoneal administration of nanocurcumin significantly increased the levels of GPO in ovarian tissues of I/R/ NC animals $(\mathrm{p}<0.05)$ (Table 1$)$.

\section{Glutathione reductase (GSHRd) analysis}

The GSHRd activities in ovarian tissue in the SSG and $\mathrm{I} / \mathrm{R}$ animals were $33.5 \pm 3.26$ and $16.4 \pm 1.27 \mathrm{u} / \mathrm{g}$ protein, respectively. Intraperitoneal administration of nanocurcumin significantly increased the levels of GSHRd in ovarian tissues of $\mathrm{I} / \mathrm{R} / \mathrm{NC}$ animals $(\mathrm{p}<0.05)$ (Table 1$)$.

TABLE 1 Comparison of the activities of SOD, NOS, MDA, MPO, GSH, GPO, GSHRd, GST and a DNA damage product of 8-OHGua/Gua in the ovarian tissues of the animals of the all experimental groups. Data are expressed as mean \pm SD.

\begin{tabular}{llllllll} 
Variables & Group SSG & Group I & Group I/R & Group I/C & Group I/R/C & Group I/NC & Group I/R/NC \\
\hline SOD $(\mathrm{mmol} / \mathrm{min} / \mathrm{mg})$ & $69.5 \pm 0.57$ & $35.8 \pm 0.22$ & $57.2 \pm 0.21$ & $53.6 \pm 0.38$ & $73.3 \pm 0.22$ & $61.3 \pm 0.42$ & $78.2 \pm 0.31^{*}$ \\
\hline $\mathrm{NOS}(\mathrm{nmol} / \mathrm{min} / \mathrm{mg})$ & $3.8 \pm 0.12$ & $3.9 \pm 0.15$ & $3.9 \pm 0.55$ & $3.2 \pm 0.12$ & $3.1 \pm 0.24$ & $3.3 \pm 0.13$ & $3.4 \pm 0.14^{*}$ \\
\hline $\mathrm{MDA}(\mu \mathrm{mol} / \mathrm{g}$ protein) & $5.7 \pm 0.19$ & $12.8 \pm 0.24$ & $11.6 \pm 0.23$ & $9.6 \pm 0.35$ & $6.8 \pm 16$ & $8.3 \pm 0.63$ & $5.4 \pm 15^{*}$ \\
\hline $\mathrm{MPO}(\mathrm{U} / \mathrm{g}$ protein) & $6.5 \pm 0.18$ & $16.7 \pm 0.43$ & $13.9 \pm 0.28$ & $12.8 \pm 0.21$ & $8.7 \pm 0.48$ & $10.7 \pm 0.12$ & $7.1 \pm 0.31^{*}$ \\
\hline $\mathrm{tGSH}(\mathrm{nmol} / \mathrm{g}$ protein) & $9.8 \pm 0.33$ & $2.9 \pm 0.22$ & $4.9 \pm 0.31$ & $5.2 \pm 0.12$ & $7.3 \pm 0.19$ & $6.4 \pm 0.22$ & $8.1 \pm 0.13^{*}$ \\
\hline GPO (U/g protein) & $38.6 \pm 2.64$ & $12.7 \pm 2.48$ & $17.6 \pm 1.41$ & $20.7 \pm 1.52$ & $29.5 \pm 2.54$ & $22.4 \pm 1.31$ & $3.25 \pm 2.66^{*}$ \\
\hline GSHRd $(\mathrm{U} / \mathrm{g}$ protein) & $33.5 \pm 2.26$ & $9.5 \pm 1.83$ & $16.4 \pm 1.27$ & $19.9 \pm 1.82$ & $24.0 \pm 2.30$ & $21.2 \pm 1.12$ & $28.5 \pm 2.53^{*}$ \\
\hline GST (U/g protein) & $21.6 \pm 1.21$ & $10.2 \pm 1.27$ & $14.7 \pm 1.38$ & $16.1 \pm 1.21$ & $19.7 \pm 1.11$ & $17.3 \pm 1.08$ & $20.5 \pm 1.21^{*}$ \\
\hline 8-OHGua/Gua (pmol/L) & $1.3 \pm 0.14$ & $2.7 \pm 0.15$ & $2.3 \pm 0.15$ & $1.7 \pm 0.13$ & $1.5 \pm 0.11$ & $1.5 \pm 0.12$ & $1.3 \pm 0.14^{*}$ \\
\hline
\end{tabular}

I: ischemia; I/R: ischemia-reperfusion; I/Nimodipine: ischemia plus intraperitoneal administration of nimodipine; $1 / \mathrm{R} /$ Nimodipine: ischemia plus reperfusion plus intraperitoneal administration of nimodipine; SOD: superoxide dismutase; NOS: nitric oxide synthase; MDA: malondialdehyde; MPO: myeloperoxidase; tGSH: total glutathione; GPO: glutathione peroxidase; GSHRd: glutathione reductase; GST: glutathione S-transferase; 8-OHGua/Gua: 8-hydroxy-2 deoxyguanine.

${ }^{*} p<0.0$ vs. other experimental groups. 


\section{Glutathione S-transferase (GST) activity}

The GST activities in ovarian tissue in the SSG and I/R animals were $21.6 \pm 1.21$ and $14.7 \pm 1.38 \mathrm{u} / \mathrm{g}$ protein, respectively. Intraperitoneal administration of nanocurcumin significantly increased the levels of GST in ovarian tissues of I/R/NC animals ( $\mathrm{p}<0.05)$ (Table 1$)$.

\section{Measurement of 8-hydroxy-2 deoxyguanine (8-OH Gua)}

The levels of 8-OHGua/Gua, a DNA damage product, were $1.3 \pm 0.14$ and $2.3 \pm 0.15 \mathrm{pmol} / \mathrm{L}$ in SSG and $\mathrm{I} / \mathrm{R}$ animals, respectively. Intraperitoneal administration of nanocurcumin significantly decreased the levels of GSHRd in ovarian tissues of $\mathrm{I} / \mathrm{R} / \mathrm{NC}$ animals $(\mathrm{p}<0.05)$ (Table 1$)$.

\section{Discussion}

The present study investigated whether intraperitoneal administration of nanocurcumin is useful in the prevention of ovarian damage in ischemia/reperfusion conditions in rat ovaries and its results revealed beneficial effects. Histopathological and biochemical assessments were performed in SSG, ischemia, ischemia-reperfusion, ischemia-controlled plus IP administration of nanocurcumin groups.

Histopathological, edema, vascular congestion, hemorrhages and leukocyte infiltration parameters were used. Biochemically, the activities of SOD, NOS, MDA, MPO, GSH, GPO, GSHRd, GST and a DNA damage product of 8-OHGua/Gua were assessed in the ovarian tissues of the animals in all of the experimental groups.

Ischemia, ischemia-reperfusion and intraperitoneal nanocurcumin applied to tissues were analyzed histopathologically. Results showed that oxidative stress level followed a parallelism with tissue damage. Edema, vascular congestion, hemorrhages and leukocyte infiltration have been used as histopathological parameters in the evaluation of cell condition. ${ }^{36}$ Edema, vascular congestion, hemorrhage and leukocyte infiltration in the $\mathrm{I} / \mathrm{R} / \mathrm{NC}$ animals were milder than in the $\mathrm{I} / \mathrm{R} / \mathrm{C}$ group.

In the present study, the levels of SOD in ovarian tissue were assessed and compared in all the experimental groups. SOD activity in SSG and IR/NC showed no significant difference. SOD is an antioxidant enzyme that catalyzes the conversion of superoxide free radical into hydrogen peroxide and molecular oxygen. SOD and endogenous antioxidant enzymes neutralize free radicals and protect tissues from the harmful effects of free radicals and active oxygen species. ${ }^{37}$ Our results showed that, in the $\mathrm{I} / \mathrm{R} / \mathrm{NC}$ animals, SOD was increased compared to those in $\mathrm{I} / \mathrm{C}$ and $\mathrm{I} / \mathrm{R} / \mathrm{C}$ groups and intraperitoneal administration of nanocurcumin protected the ovarian tissue against ischemia-reperfusion injury.
It has been demonstrated that hypoxia generates iNOSs, which plays an important damaging role in $\mathrm{I} / \mathrm{R}$ injury. ${ }^{38}$ iNOS is increased after cellular stimulation via cytokines in macrophages, neutrophils, and microglia and may also contribute to late-stage tissue injury. ${ }^{39}$ iNOS derives primarily from the polymorphonuclear neutrophilic leukocytes during reperfusion, and down-regulation of iNOS could limit cell injury caused by hypoxia. ${ }^{40,41}$ Our findings showed that the iNOS levels in ovarian tissue of I and I/R rats were increased compared to those of the SSG animals. Down-regulation of iNOS could limit cell injury caused by hypoxia. Our results showed that, in the I/R/NC animals, iNOS was down-regulated compared to those in I/C and I/R/C. Thus, intraperitoneal administration of $1 \mathrm{mg} / \mathrm{kg}$ nanocurcumin protected ovarian tissue against ischemia-reperfusion injury to a greater extent than $100 \mathrm{mg}$ curcumin.

MDA is a lipid peroxidation product and occurs as a result of the peroxidation of fatty acids that contain three or more double bonds. MDA causes cross-linking of membrane components and leads to negative consequences such as changes in ion permeability and enzyme activity by affecting ion exchange through the cell membranes. ${ }^{42,43} \mathrm{MDA}$ levels in the present study were found to be much lower in $\mathrm{I} / \mathrm{R} / \mathrm{NC}$ animals compared to those in the other experimental groups. This could protect the tissues against ischemia-reperfusion injury in nanocurcumin-treated animals.

MPO is produced by neutrophils and macrophages, it catalyzes the reaction between hydrogen peroxide and chlorine and results in the toxic compound hypochlorous acid. Hypochlorous acid is involved in the formation of the hydroxyl radical. ${ }^{44,45}$ It has been demonstrated that MPO activity is increased in ischemia-reperfusion induced ovarian tissue. ${ }^{46}$ This finding was in agreement with results of our study. MPO activity was suppressed in nanocurcumin-treated animals of our study.

GSH is an antioxidant used to measure oxidative stress. Reperfusion after ischemia is reported to cause severe damage to ovarian tissue and suppress the GSH levels. ${ }^{36} \mathrm{GSH}$ plays a role in the protection of cells against oxidative stress and toxic compounds as well as the metabolic processing of many endogenous compounds such as estrogen, prostaglandin and leukotrienes. ${ }^{47} \mathrm{GSH}$, as an antioxidant, reacts with peroxides and free radicals and converts them into harmless products and subsequently protects the cells against the potential oxidative damage of free radicals. These findings were in agreement with our results. We found that oxidative stress was minimized and the severe damage due to sudden reperfusion was 
prevented in nanocurcumin-treated animals to a greater extent than seen in curcumin-treated animals.

GPO activity is significantly reduced in tissues undergoing oxidative stress-related conditions, as in ischemia-reperfusion injury. ${ }^{48} \mathrm{GPO}$ detoxifies the hydrogen peroxide radical that forms in the cell by converting it to water and prevents the formation of more toxic products from hydrogen peroxide radical. ${ }^{49}$ In the present study, a significant decrease in GPO activity was observed in ovarian tissues of $\mathrm{I} / \mathrm{R} / \mathrm{NC}$ animals.

GSH is oxidized during the detoxification of hydrogen peroxide radical. GSHRd is a NADPH-dependent enzyme that converts oxidized glutathione to reduced glutathione. ${ }^{50}$ GSHRd is reported to show higher activity in healthy tissue and, in parallel with tissue damage, its activity is decreased..$^{51}$ In our study, activity of GSHRd was significantly increased in nanocurcumin-treated animals compared to those in $\mathrm{I} / \mathrm{C}$ and $\mathrm{I} / \mathrm{R} / \mathrm{C}$ groups.

GST binds foreign substances to the -SH group of cysteine in glutathione, neutralizes the electrophilic regions and protects the cells from the harmful effects of foreign substance regions..$^{52}$ Activity of GST has been reported to be suppressed in oxidative tissue injury induced by ischemia. ${ }^{52}$ Consistently, our findings showed that GST activity in ovarian tissue of nanocurcumin-treated animals was significantly lower than those in $\mathrm{I} / \mathrm{C}$ and $\mathrm{I} / \mathrm{R} / \mathrm{C}$ groups.

DNA molecules are damaged if free radicals are in close proximity to the DNA molecules. ${ }^{53}$ Hydroxyl radical reacts very easily with deoxyribose and the bases, causing DNA damage through extracting hydrogen from nucleic acids or reacting with double bonds. ${ }^{54} 8-\mathrm{OH}$ Gua is considered an important marker of DNA oxidation..$^{55}$ Our findings showed that the ovarian tissues of $\mathrm{I} / \mathrm{C}$ and I/R/C animals had higher levels of 8-OHGua than those of SSG animals. Nevertheless, our results showed that there were no significant difference between SSG and nanocurcumin-treated animals regarding the levels of DNA damage.

There are many studies in the literature about the improvement of ischemia reperfusion injury. Studies demonstrated that the agents with antioxidant or anti-inflammatory activities may be beneficial in reducing ovarian ischemia reperfusion injury. Also, studies revealed the beneficial effect of controlled reperfusion in the prevention of ovarian tissue damage. In spite of the profuse literature, ischemia/reperfusion damage continues to be a serious problem clinically. Essentially, early diagnosis and treatment of ovarian torsion plays an important role to provide urgent protection against life-threatening complications from ischemia and to prevent future infertility. ${ }^{56}$
Curcumin has been reported as a useful agent both for the prevention and treatment of $\mathrm{I} / \mathrm{R}$ injury in many organs. ${ }^{57}$ These protective effects are mainly believed to be based on inhibitory actions of curcumin on diseasemediated induction of inflammatory transcription factors, protein kinases, adhesion molecules, oxidative stress and inflammation. ${ }^{57}$ The administration of curcumin has reported to reduce the generation of reactive oxygen species (ROS), monocyte adhesion, phosphorylation of c-Jun $\mathrm{N}$-terminal kinase (JNK), p38 MAP kinase, and signal transducer and activator of transcription (STAT)-3 in TNF-a-stimulated cells. ${ }^{57}$ It has also been documented that the administration of curcumin prior to conservative surgery (detorsion) provides a significant decrease in the oxidative stress markers in the ovarian tissues. ${ }^{21}$ The comparison between oxidative status and antioxidative status is clear enough to suggest that the administration of curcumin, as reported previously, leads to a decrease in the oxidative stress and an increase in antioxidation. ${ }^{21}$

Nano-sized particles ranging below several $10 \mathrm{~nm}$ are of great interest, because of the chemical and physical behavior of the particles arising from a quantum size effect, which is remarkably different from those in bulk and provides a great potential for use in practice. ${ }^{58}$ The findings of the present study showed that nanocurcumin at very low concentrations, $1 \mathrm{mg} / \mathrm{kg}$ nanocurcumin versus $100 \mathrm{mg}$ curcumin, produced significant improvements compared to native curcumin.

Substances are administered by a wide variety of routes. A key factor determining the route selected is whether the agent is being administered for a local or systemic (either enteral or parenteral) effect. Parenteral administration methods typically produce the highest bioavailability of substances because these methods avoid the first-pass effect of hepatic metabolism, which occurs commonly with orally-administered drugs. ${ }^{58}$ Intraperitoneal administration seems more effective and may increase drug availability if oral administration poses any difficulties. It is clear that transperitoneal absorption of the agent is much faster than oral administration. ${ }^{25}$ Timely treatment is very important in emergency conditions such as ovarian torsion.

In conclusion, histopathological results obtained from all the experimental groups were consistent with the results of the biochemical analyses indicating that intraperitoneal administration of nanocurcumin can be helpful in minimizing ischemia-reperfusion injury in ovarian tissue exposed to ischemia. Regarding the transperitoneal absorption of nanocurcumin, which is much faster than its oral administration, transperitoneal ad- 
ministration of nanocurcumin seems useful when ovarian torsion takes place. This may help the patients preserve their future fertility. Our study demonstrated that intraperitoneal administration of $1 \mathrm{mg} / \mathrm{kg}$ nanocurcumin can improve ischemia-reperfusion injury in ovarian tissue exposed to ischemia. Thus, dose-response studies should be conducted for nanocurcumin to determine its maximal efficacy in minimizing ischemia-reperfusion injury in ovarian tissue.

\section{ACKNOWLEDGMENTS}

The authors would like to thank Dr. Rahim Mohammadi, Department of Surgery and Diagnostic Imaging for proofreading the manuscript.

\section{REFERENCES}

1. Oelsner G, Shashar D. Adnexal torsion. Clin Obstet Gynecol. 2006; 49(3):459-63.

2. Geimanaite L, Trainavicius K. Ovarian torsion in children: management and outcomes. J Pediatr Surg. 2013; 48(9):1946-53.

3. Celik A, Ergün O, Aldemir H, Ozcan C, Ozok G, Erdener A, et al. Long-term results of conservative management of adnexal torsion in children. J Pediatr Surg. 2005; 40(4):704-8.

4. Carden DL, Granger DN. Pathophysiology of ischaemia-reperfusion injury. J Pathol. 2000; 190(3):255-66.

5. Zimmerman BJ, Granger DN. Reperfusion injury. Surg Clin North Am. 1992; 72(1):65-83.

6. Nakagiri A, Sunamoto M, Takeuchi K, Murakami M. Evidence for the involvement of NADPH oxidase in ischemia/reperfusion-induced gastric damage via angiotensin II. J Physiol Pharmacol. 2010; 61(2):171-9.

7. Halliwell B, Gutteridge JM. Free radicals in biology and medicine. London: Oxford University Press; 1999.

8. Ingec M, Isaoglu U, Yilmaz M, Calik M, Polat B, Alp HH, et al. Prevention of ischemia-reperfusion injury in rat ovarian tissue with the on-off method. J Physiol Pharmacol. 2011; 62(5):575-82.

9. Wilhelm Filho D, Torres MA, Bordin AL, Crezcynski-Pasa TB, Boveris A. Spermatic cord torsion, reactive oxygen and nitrogen species and ischemiareperfusion injury. Mol Aspects Med. 2004; 25(1-2):199-210.

10. Girotti AW. Lipid hydroperoxide generation, turnover, and effector action in biological systems. J Lipid Res. 1998; 39(8):1529-42.

11. Huang HY, Helzlsouer KJ, Appel LJ. The effects of vitamin C and vitamin E on oxidative DNA damage: results from a randomized controlled trial. Cancer Epidemiol Biomarkers Prev. 2000; 9(7):647-52.

12. Ames BN, Shigenaga MK, Hagen TM. Oxidants, antioxidants, and the degenerative diseases of aging. Proc Natl Acad Sci U S A. 1993; 90(17):7915-22.

13. Oral A, Odabasoglu F, Halici Z, Keles ON, Unal B, Coskun AK, et al. Protective effects of montelukast on ischemia-reperfusion injury in rat ovaries subjected to torsion and detorsion: biochemical and histopathologic evaluation. Fertil Steril. 2011; 95(4):1360-6.

14. Mogilner JG, Lurie M, Coran AG, Nativ O, Shiloni E, Sukhotnik I. Effect of diclofenac on germ cell apoptosis following testicular ischemia-reperfusion injury in a rat. Pediatr Surg Int. 2006; 22(1):99-105.

15. Halici Z, Karaca M, Keles ON, Borekci B, Odabasoglu F, Suleyman H, et al. Protective effects of amlodipine on ischemia-reperfusion injury of rat ovary: biochemical and histopathologic evaluation. Fertil Steril. 2008; 90(6):2408-15.

16. Anderson AM, Mitchell MS, Mohan RS. Isolation of curcumin from turmeric. J Chem Educ. 2000; 77(3):359-60.

17. Pizzo P, Scapin C, Vitadello M, Florean C, Gorza L. Grp94 acts as a mediator of curcumin-induced antioxidant defence in myogenic cells. J Cell Mol Med. 2010; 14(4):970-81.

18. Aggarwal BB, Harikumar KB. Potential therapeutic effects of curcumin, the anti-inflammatory agent, against neurodegenerative, cardiovascular, pulmonary, metabolic, autoimmune and neoplastic diseases. Int J Biochem Cell Biol. 2009; 41(1):40-59.
19. Wang Y, Lu Z, Wu H, Lv F. Study on the antibiotic activity of microcapsule curcumin against foodborne pathogens. Int J Food Microbiol. 2009; 136(1):71-4.

20. Jovanovic SV, Boone CW, Steenken S, Trinoga M, Kaskey RB. How curcumin works preferentially with water soluble antioxidants. J Am Chem Soc. 2001; 123(13):3064-8.

21. Sak ME, Soydinc HE, Sak S, Evsen MS, Alabalik U, Akdemir F, et al. The protective effect of curcumin on ischemia-reperfusion injury in rat ovary. Int J Surg. 2013; 11(9):967-70.

22. Flora G, Gupta D, Tiwari A. Nanocurcumin: a promising therapeutic advancement over native curcumin. Crit Rev Ther Drug Carrier Syst. 2013; 30(4):331-68.

23. Cortés-Sanabria L, Paredes-Ceseña CA, Herrera-Llamas RM, Cruz-Bueno Y, Soto-Molina H, Pazarín L, et al. Comparison of cost-utility between automated peritoneal dialysis and continuous ambulatory peritoneal dialysis. Arch Med Res. 2013; 44(8):655-61.

24. Chaudhary K, Haddadin S, Nistala R, Papageorgio C. Intraperitoneal drug therapy: an advantage. Curr Clin Pharmacol. 2010; 5(2):82-8.

25. Bhawana, Basniwal RK, Buttar HS, Jain VK, Jain N. Curcumin nanoparticles: preparation, characterization, and antimicrobial study. J Agric Food Chem. 2011; 59(5):2056-61.

26. Zimmermann M. Ethical guidelines for investigations of experimental pain in conscious animals. Pain. 1983; 16(2):109-10.

27. Sun Y, Oberley LW, Li Y. A simple method for clinical assay of superoxide dismutase. Clin Chem. 1988; 34(3):497-500.

28. Feelisch M, Noack EA. Correlation between nitric oxide formation during degradation of organic nitrates and activation of guanylate cyclase. Eur J Pharmacol. 1987; 139(1):19-30.

29. Knowles RG, Merrett M, Salter M, Moncada S. Differential induction of brain, lung and liver nitric oxide synthase by endotoxin in the rat. Biochem J. 1990; 270(3):833-6

30. Ohkawa $\mathrm{H}$, Ohishi $\mathrm{N}$, Yagi K. Assay for lipid peroxides in animal tissues by thiobarbituric acid reaction. Anal Biochem. 1979; 95(2):351-8.

31. Wei H, Frenkel K. In vivo formation of oxidized DNA bases in tumor promoter-treated mouse skin. Cancer Res. 1991; 51(16):4443-9.

32. Sedlak J, Lindsay RH. Estimation of total, protein-bound, and nonprotein sulfhydryl groups in tissue with Ellman's reagent. Anal Biochem. 1968; 25(1):192-205.

33. Lawrence RA, Burk RF. Glutathione peroxidase activity in selenium-deficient rat liver. 1976. Biochem Biophys Res Commun. 2012; 425(3):503-9.

34. Carlberg I, Mannervik B. Glutathione reductase. Methods Enzymol. 1985; 113:484-90.

35. Habig WH, Jakoby WB. Assays for differentiation of glutathione S-transferases. Methods Enzymol. 1981; 77:398-405.

36. Celik O, Turkoz Y, Hascalik S, Hascalik M, Cigremis Y, Mizrak B, et al. The protective effect of caffeic acid phenethyl ester on ischemia-reperfusion injury in rat ovary. Eur J Obstet Gynecol Reprod Biol. 2004; 117(2):183-8.

37. Arosio B, Gagliano N, Fusaro LM, Parmeggiani L, Tagliabue J, Galetti P, et al. Aloe-Emodin quinone pretreatment reduces acute liver injury induced by carbon tetrachloride. Pharmacol Toxicol. 2000; 87(5):229-33.

38. Chatterjee PK, Patel NS, Kvale EO, Cuzzocrea S, Brown PA, Stewart KN, et al. Inhibition of inducible nitric oxide synthase reduces renal ischemia/ reperfusion injury. Kidney Int. 2002; 61(3):862-71.

39. Jeddi S, Zaman J, Zadeh-Vakili A, Zarkesh M, Ghasemi A. Involvement of inducible nitric oxide synthase in the loss of cardioprotection by ischemic postconditioning in hypothyroid rats. Gene. 2016; 580(2):169-76.

40. Ferdinandy P, Schulz R. Nitric oxide, superoxide, and peroxynitrite in myocardial ischaemia-reperfusion injury and preconditioning. Br J Pharmacol. 2003; 138(4):532-43.

41. Valko M, Morris H, Cronin MT. Metals, toxicity and oxidative stress. Curr Med Chem. 2005; 12(10):1161-208.

42. Niki E, Yoshida Y, Saito Y, Noguchi N. Lipid peroxidation: mechanisms, inhibition, and biological effects. Biochem Biophys Res Commun. 2005; 338(1):668-76.

43. Ximenes VF, Paino IM, Faria-Oliveira OM, Fonseca LM, Brunetti IL. Indole ring oxidation by activated leukocytes prevents the production of hypochlorous acid. Braz J Med Biol Res. 2005; 38(11):1575-83.

44. Van Antwerpen P, Boudjeltia KZ, Babar S, Legssyer I, Moreau P, Moguilevsky $\mathrm{N}$, et al. Thiol-containing molecules interact with the myeloperoxidase/ $\mathrm{H} 2 \mathrm{O} 2 /$ chloride system to inhibit LDL oxidation. Biochem Biophys Res Commun. 2005; 337(1):82-8.

45. Isaoglu U, Yilmaz M, Sener E, Cetin N, Altuner D, Bilen H, et al. The impaired balances of oxidant/antioxidant and COX-1/COX-2 in ovarian 
ischemia-reperfusion injury and prevention by nimesulide. Lat Am J Pharm. 2012; 31(10):1481-8.

46. Meister A. Glutathione deficiency produced by inhibition of its synthesis, and its reversal; applications in research and therapy. Pharmacol Ther. 1991; 51(2):155-94.

47. Celebi F, Akbas A, Saglam MB. Effect of sertraline in indomethacin-induced gastric mucosal damage. Asian J Chem. 2012; 24(5):1966-70.

48. Valko M, Rhodes CJ, Moncol J, Izakovic M, Mazur M. Free radicals, metals and antioxidants in oxidative stress-induced cancer. Chem Biol Interact. 2006; 160(1):1-40

49. Sharma H, Zhang X, Dwivedi C. The effect of ghee (clarified butter) on serum lipid levels and microsomal lipid peroxidation. Ayu. 2010;31(2):134-40.

50. Polat B, Suleyman $\mathrm{H}, \mathrm{Alp} \mathrm{HH}$. Adaptation of rat gastric tissue against indomethacin toxicity. Chem Biol Interact. 2010; 186(1):82-9.

51. Shi HY, Li ZH, Zhang YX, Chen L, Xiang DY, Zhang YF. Two pear glutathione $\mathrm{S}$-transferases genes are regulated during fruit development and involved in response to salicylic acid, auxin, and glucose signaling. PLoS One. 2014; 9(2):e89926.
52. Mansoorali KP, Prakash T, Kotresha D, Prabhu K, Rama Rao N. Cerebroprotective effect of Eclipta alba against global model of cerebral ischemia induced oxidative stress in rats. Phytomedicine. 2012; 19(12):1108-16.

53. Milligan JR, Aguilera JA, Nguyen TT, Ward JF, Kow YW, He B, et al. Yield of DNA strand breaks after base oxidation of plasmid DNA. Radiat Res. 1999; 151(3):334-42.

54. Grollman AP, Moriya M. Mutagenesis by 8-oxoguanine: an enemy within. Trends Genet. 1993; 9(7):246-9

55. Aksoy AN. Ovarian ischemia-reperfusion injury: a brief review. SM J Gynecol Obstet. 2015; 1(2):1008-111.

56. Srivastava G, Mehta JL. Currying the heart: curcumin and cardioprotection. J Cardiovasc Pharmacol Ther. 2009; 14(1):22-7.

57. Okuyama K, Lenggoro IW. Nanoparticle Project in NEDO's nanotechnology materials program: recent research reviews" PARTEC 2004, Nurnberg, Germany 16-18 32004.

58. Turner PV, Brabb T, Pekow C, Vasbinder MA. Administration of substances to laboratory animals: routes of administration and factors to consider. J Am Assoc Lab Anim Sci. 2011; 50(5):600-13. 